\title{
DIMENSIONES CULTURALES E IDENTIDADES SITUADAS: LA HERENCIA MAYA EN MIGRANTES YUCATECOS A ESTADOS UNIDOS
}

\author{
Pedro Antonio Be Ramírez \\ Facultad de Filosofía y Letras / Instituto de Investigaciones Antropológicas, \\ Universidad Nacional Autónoma de México
}

Resumen: Este artículo trata sobre la conformación identitaria de los migrantes de Telchac Pueblo a partir de algunos elementos culturales vinculados con su herencia maya ancestral. Las dimensiones culturales que aquí se presentan no son únicas ni mucho menos absolutas para explicar el pasado maya en Yucatán; más bien corresponden a ciertos aspectos que permiten comprender la manera en cómo los migrantes yucatecos se conciben a sí mismos desde discursos y prácticas situados en contextos sociales reales. Las bases o dimensiones culturales consideradas emblemas que otorgan carácter distintivo a la identidad son el eje central y admiten dar cuenta del mantenimiento, la reelaboración y lo situacional de las costumbres y tradiciones en esta región del sureste mexicano.

Palabras clave: dimensiones culturales, migrantes, identidad yucateca, Telchac Pueblo, herencia cultural maya.

ABSTRACT: This article focuses on the conformation of identity of migrants from Telchac Pueblo, Yucatan, viewed initially as cultural elements that play out Mayan ancient heritage. The cultural dimensions presented here are not unique, and much less absolute in explaining Yucatan's Mayan past. Rather they correspond to certain aspects that allow us to understand the ways in which yucatecan migrants conceive themselves within current situated discourse practices. The bases or cultural dimensions considered are emblematic and grant distinctive character to local identity: they are seen as a central axis that allows for comprehension of cultural persistence (or resistance), the (re) elaboration of customs and the situational features of traditions within this Mexican southeast region.

Kerwords: Cultural practice, migrants, yucatecan identity, Telchac Pueblo, Mayan cultural heritage.

RECEPCIÓN: 15 de septiembre del 2010.

ACEPTACIÓN: 1 de diciembre del 2010. 



\title{
DIMENSIONES CULTURALES E IDENTIDADES SITUADAS: LAHERENCIA MAYAEN MIGRANTES YUCATECOS A ESTADOS UNIDOS"
}

\author{
Pedro Antonio Be Ramírez \\ Facultad de Filosofía y Letras / Instituto de Investigaciones Antropológicas, \\ Universidad Nacional Autónoma de México
}

\section{Introducción}

La historia de la migración internacional yucateca inicia con las primeras incursiones de trabajadores temporales inscritos al Programa Bracero (1942-1964), principalmente a mediados de la década de 1950 e inicios de la de 1960, poco antes de concluir el convenio binacional. A partir de ese entonces y durante los años ochenta, en municipios como Oxkutzcab, Peto, Tekax, Motul y Cenotillo continuó el éxodo de trabajadores incrementando el flujo migratorio; pero fue hasta la siguiente década, la de los noventa, cuando la presencia de los yucatecos se hace más visible y el hecho de migrar se extiende a todas las regiones socioeconómicas y culturales de Yucatán (Fortuny Loret de Mola, 2004; Lewin Fischer, 2007).

El estado de California ha sido el lugar de destino que concentra a la mayoría de los yucatecos y es ahí, particularmente en la ciudad de Oxnard, condado de Ventura, donde se localiza un grupo importante de paisanos: los de Telchac Pueblo. El primer referente sobre la migración internacional telchaqueña es la incorporación de campesinos temporales a la agricultura del suroeste de los Estados Unidos entre 1959 y 1967. Uno de los aspectos fundamentales para emigrar, en ese tiempo, fue el declive de la producción henequenera en el estado desde principios del siglo xx hasta agravarse a mediados del mismo; esto propició la búsqueda de nuevas oportunidades de empleo para el beneficio de sus familias.

Junto a estos trabajadores, un flujo paralelo de migrantes telchaqueños se les une durante la década de 1950 bajo la modalidad de "emigrados" con la finali-

\footnotetext{
Agradezco a la doctora Patricia Fortuny Loret de Mola por su acompañamiento en la dirección de este estudio. Estoy en deuda con la doctora Claudia Jean Harriss Clare por sus observaciones y comentarios críticos a la última versión de este documento. Asimismo a los lectores anónimos cuyas apreciaciones enriquecieron en gran medida mis reflexiones preliminares. Finalmente, toda mi gratitud a la gente de Telchac Pueblo, tanto migrantes como aquellos que permanecen en la localidad, por la confianza y disponibilidad para compartir sus historias y experiencias de vida, siendo pretexto este texto para hacérselos saber.
} 
dad de ayudar a otros del mismo pueblo y para facilitar y asegurar su estancia laboral y la obtención de vivienda en el nuevo sitio de llegada. Así, los primeros migrantes telchaqueños hicieron posible establecerse en esta ciudad cuando el mecanismo para "traer" a la familia o vecinos en aquel momento lo consentía. Con el tiempo, los medios para cruzar se modificaron al utilizar estrategias peligrosas por medio de coyotes o polleros y sufrir, en algunos casos, las consecuencias. Una de las razones para explicar la presencia de los telchaqueños en este lugar consiste en que muchos braceros y los primeros emigrados llegaron a Oxnard para trabajar en el field o plantíos, aunque sus áreas laborales se han diversificado conforme al paso del tiempo.

De cualquier forma, estos yucatecos se han extendido hacia otras ciudades y estados de la Unión Americana como Arizona, Texas y Utah, y han contribuido a consolidar la ruta y la red de migrantes telchaqueños hasta nuestros días. Aún así, dentro del conjunto de estudios generados sobre el fenómeno migratorio en municipios del estado de Yucatán como Peto, Oxkutzcab, Motul o Tunkás, esta localidad enclavada en la zona ex henequenera no figura. Sin embargo, los acontecimientos históricos, sociales y económicos que han impactado esta región, aunados a la experiencia del intercambio constante de remesas, discursos, prácticas y tradiciones, dinamiza la vida sociocultural de los migrantes telchaqueños permitiéndoles reconfigurar ambos espacios sociales, aquí y allá, en un mismo escenario transnacional. ${ }^{1}$

El presente artículo estudia la conformación identitaria de los migrantes de Telchac Pueblo a partir de algunos elementos (prácticas) culturales y con respecto a su herencia maya ancestral. Las dimensiones culturales que aquí se proponen para su discusión no son únicas ni mucho menos absolutas para explicar el pasado maya en Yucatán; más bien se refieren a ciertos aspectos que admiten comprender la manera en cómo los migrantes yucatecos se conciben a sí mismos desde sus discursos y prácticas situados. Las bases o dimensiones culturales consideradas emblemas que otorgan carácter distintivo a la identidad (Bartolomé, 2004), son el eje central para este documento. ${ }^{2}$ El análisis que se ofrece deriva de una investigación propia realizada para el posgrado y enfocada en migrantes de Telchac Pueblo hacia Estados Unidos; aquella permite dar cuenta del mantenimiento, la reelaboración, la reinvención y lo situacional de las costumbres y tradiciones en estas tierras del Mayab (Be Ramírez, 2010).

Como herencia cultural maya intento definir el conjunto de prácticas, discursos, normas, valores y costumbres que comprende la cotidianeidad de los yucatecos

\footnotetext{
${ }^{1}$ Por transnacionalismo se entiende una corriente de análisis del proceso social donde los vínculos multilocales o translocales se vuelven espacios de interconexión sociocultural, es decir, entornos de socialización, identificación, reproducción e intercambio de experiencias, normas, valores y creencias entre los ausentes, quienes no emigraron y las comunidades de partida y llegada.

${ }^{2}$ Algunas de las bases culturales ampliamente tratadas por Bartolomé (2004) como referentes para los grupos étnicos son la lengua, el territorio, la religión, la indumentaria, la vida cotidiana, la historia, el sistema económico, la adscripción parental y la participación política.
} 
a través de la socialización de generación a generación. Dichos aspectos compartidos e incorporados a la realidad yucateca otorgan sentido a la vida social y comunitaria, pues suscriben la continuación, elaboración y/o (re)invención de la cultura maya materializándose en el territorio (físico o simbólico), la lengua, la culinaria regional, las creencias, los comportamientos, las festividades, las tradiciones y las ceremonias o los rituales mayas. Esta invención/reinvención posibilita participar en los símbolos y visiones del mundo incluso más allá del terruño, para así reconocer otras formas de ser y sentirse en y de Yucatán, es decir, de reafirmar su identidad cultural como maya yucateca. La invención, ${ }^{3}$ como lo propone Castañeda (1995: 184), “es un acto de apropiación” a partir de una lógica y representación que los vincula con su pasado maya, su cultura ancestral, en una cultura maya yucateca contemporánea.

El trabajo etnográfico, fundamental en todo estudio antropológico, constituye el hilo conductor que reúne las diversas herramientas metodológicas propuestas para realizar este acercamiento a la migración yucateca internacional a partir de entrevistas, pláticas cotidianas, la observación participativa con los telchaqueños y estancias periódicas en ambos escenarios de investigación durante el 2007 y el 2008. La convivencia en Telchac Pueblo y Oxnard forjó relaciones de amistad y confianza genuinas que contribuyeron a participar en celebraciones, reuniones e inclusive en la misma fiesta patronal durante los últimos días de septiembre y principios de octubre. La colaboración y el apoyo recibidos de los telchaqueños para compartir sus conocimientos, experiencias y sentimientos me llevó a dilucidar, en cierta medida, las formas cotidianas de (con)vivir en uno de los municipios yucatecos cuya historia social y cultural ha permeado su existencia.

Para iniciar esta discusión sobre los migrantes yucatecos y los componentes socioculturales que conforman sus identidades, primero presento un panorama general del municipio destacando algunos aspectos que dan singularidad a la vida cotidiana del lugar. En la segunda sección analizo la evidente multiplicidad de identificaciones y representaciones que surgen de propios y ajenos en la entidad, particularmente alrededor del debate actual sobre la etnicidad en Yucatán. La tercera aborda las diversas interpretaciones que los migrantes telchaqueños elaboran del "sí mismo" con base en dimensiones o elementos culturales: la pertenencia al territorio (pueblo), la lengua, la culinaria regional y la identidad maya, todo ello desde una postura situacional. En la última sección planteo algunas reflexiones finales sobre la particularidad de vivir y pertenecer a una cul-

\footnotetext{
${ }^{3}$ La conceptualización de invención/reinvención planteada por Castañeda (1995: 184) admite la noción de recreación, transformación, reapropiación y singularidad en la construcción de la identidad cultural aquí propuesta, ya que la invención "nunca es la creación de algo verdaderamente nuevo, pero sí, la reformulación o reproducción de lo que ya existe aunque en forma nueva; al mismo tiempo, invención no es la reproducción de lo idéntico, pero sí, la producción de cambios y alteraciones en lo tradicional. El concepto de invención o reinvención capta las ideas de continuidad e igualdad tanto como las de ruptura y diferencia”. Es, pues, una construcción social de la identidad. Sobre la perspectiva de identidad cultural, véase en particular el trabajo de Solís Lizama y Fortuny Loret de Mola (2010).
} 
tura ancestral como la maya, al mismo tiempo que se organiza la vida social y comunitaria de los telchaqueños dentro de un contexto migratorio como el que experimentan.

\section{Telchac Pueblo, un municipio ex henequenero}

Cercano a la costa yucateca, en la extensión centro-norte del estado, se localiza Telchac Pueblo o "lugar de muchas raíces largas y pronunciadas", como las de algunos árboles que en ciertas ocasiones estorban el paso en los caminos (Tec Chi, 1981), a casi 60 kilómetros de Mérida. Después de su separación como parte del ayuntamiento de Motul durante el primer cuarto del siglo pasado, el municipio estuvo conformado por Telchac Puerto y Telchac Pueblo; este último funcionaba como cabecera municipal. Para el 8 de julio de 1932 ambos pueblos se independizan para convertirse en municipios autónomos cuyo punto costero llamado Miramar se desliga del municipio de Telchac Pueblo. Actualmente, su población es de unos 3404 habitantes de acuerdo al II Conteo de Población y Vivienda 2005 y representa el 0.20 por ciento en relación al total censal estatal (INEGI, 2007). Con respecto a los migrantes, tan sólo en Oxnard se estima que viven unos 150 telchaqueños sin considerar a otras ciudades y estados de la Unión Americana donde los paisanos residen. ${ }^{4}$

Este municipio cuenta con 1056 hogares cuyas viviendas habitadas suman un total de 1042; un 98 por ciento de ellas cuenta con piso de cemento o de algún otro material, en tanto el 2 por ciento de las viviendas tienen piso de tierra (INEGI, 2007). La mayoría de ellas está hecha con material de concreto, mientras de manera escasa se observan las "tradicionales casas mayas", es decir, casas ovaladas o rectangulares con paredes de bajareque ${ }^{5}$ y techo de huano, ${ }^{6}$ o paja, de dos aguas (foto 1). La actividad económica de la región, según indica el INEGI (2001), se basa en una Población Económicamente Activa (PEA) de 1280 personas en el año 2000, en contraste con los 1256 habitantes económicamente inactivos.

Del total de la PEA, cerca de 1271 individuos se encuentran distribuidos en los siguientes sectores productivos: un 38 por ciento se ocupa en actividades turísticas, en el comercio y en los servicios del sector terciario. Las actividades agrícolas, ganaderas, de cacería y pesca del sector primario conforman el 35 por

\footnotetext{
${ }^{4}$ Esta última apreciación es producto de la puesta en marcha del Programa $3 \times 1$ en el verano del 2008 cuya primera actividad fue el renovar los puestos ubicados en la plaza principal del pueblo. La presente aclaración es para cuestionar el dato reportado por el INEGI en 2007 que no refleja (por mucho) a la población migrante de Telchac.

${ }^{5}$ El bajareque, o chuy che' en lengua maya, es un conjunto de varas de árbol que se entreteje y se cubre con una pasta de barro y zacate para darle consistencia a las paredes.

${ }^{6}$ El huano, o xa'n en lengua maya, es la hoja del ch'it (Thrinax radiata Lodd. ex J.A. \& J.H. Schult.) que crece de forma similar a la palmera. Al secarse se utiliza para construir los techos; así se protege y se refresca la vivienda.
} 


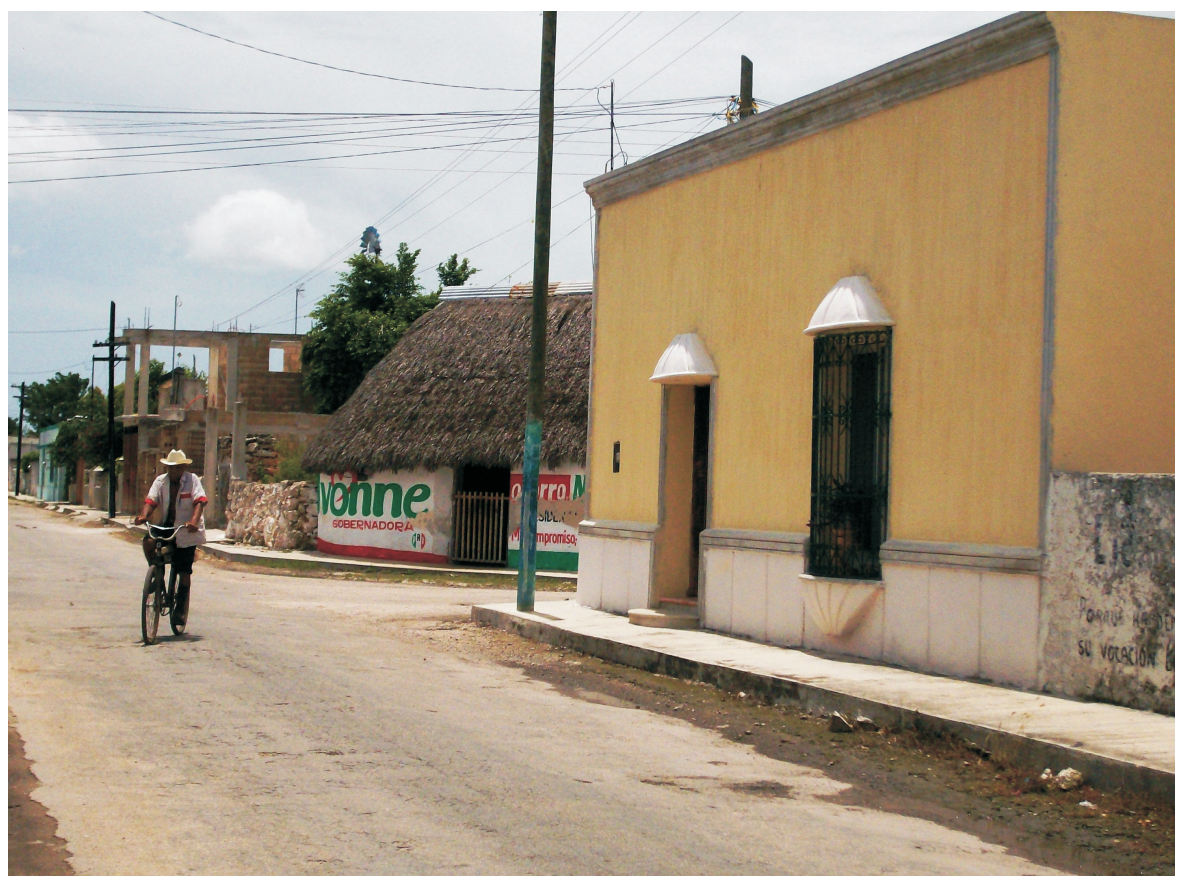

Figura 1. Telchac Pueblo: contraste entre viviendas modernas y una "casa tradicional maya". Foto del autor

ciento. Las labores relacionadas con el sector secundario - que abarca la industria manufacturera, de construcción, de electricidad, de minería y del petróleoconstituye casi el 26 por ciento. Por último, un porcentaje mínimo ( 0.71 por ciento) corresponde a quienes se hallan en otras actividades productivas. Como se aprecia, las labores vinculadas con el turismo y los servicios sustentan en buena medida la economía local, además de explicar las migraciones interregionales de los telchaqueños hacia zonas como el Caribe mexicano, por ejemplo.

Antaño, una de las principales actividades de la realidad agrícola en Yucatán fue la agroindustria henequenera en la llamada zona ex henequenera ${ }^{7}$ localizada

${ }^{7}$ En cuanto a las regiones o zonas de Yucatán, Villanueva Mukul indica la conformación a partir de la década de 1980 de "tres regiones agrícolas, una agropecuaria y una extractiva-industrial: la henequenera, la citrícola, la maicera, la ganadera y la litoral-pesquera” (1990b: 89-92); por su parte, Quintal Avilés et al. (2003a) proponen cuatro zonas en el estado: la ex henequenera se ubica al noroeste, la región Puuc o Sierrita se sitúa al sur, la zona maicera "tradicional” está al oriente; finalmente la región ganadera, al norte de Yucatán. En tanto, Guzmán Medina (2005) opta por una regionalización más general al dividir a Yucatán en cuatro zonas vinculadas con procesos económicos-productivos: la henequenera, la maicera-ganadera, la citrícola y la costera. Para una revisión más detallada sobre la regionalización, consúltese Villanueva Mukul, 1990b. 
en la porción noroccidental del estado de la cual Telchac Pueblo forma parte. ${ }^{8}$ Tanto así que hoy en día algunos hombres se dedican a las labores del cultivo (la milpa o la siembra) o a actividades henequeneras (corte y raspado, entre otras) de forma mínima. No obstante que el municipio vivió el auge y debacle de la producción henequenera, la cual marcó un hito en su desarrollo social y económico, diversos procesos de cambio social e histórico han impactado la región: "el contacto" dependiente y subordinado de los "mayas" con la aristocracia "blanca yucateca" desde mediados del siglo xix, la Guerra de Castas de 1847 y su continuación hasta ya entrado el siglo xx, así como el esplendor y ocaso de las haciendas henequeneras (Baños Ramírez, 1989; Villanueva Mukul, 1990a, 1990b). Así, resulta cierto que en el pueblo existe una descaracterización cultural, es decir, una menor vinculación con su pasado cultural maya según se explica a continuación.

Tal como se ha dicho de otros municipios de esta región socioeconómica, así como lo refieren algunos habitantes del pueblo con quienes conviví, en Telchac ha disminuido la realización de ciertas prácticas, usos y costumbres característicos de la entidad. Tal es el caso de rituales domésticos como el hetzmek; ${ }^{9}$ de ceremonias de petición de lluvias para proteger la milpa como el ch'a' cháak $;^{10}$ de leyendas respecto a los aluxes, los encargados de proteger y cuidar la milpa; o bien, el hablar la lengua maya. En relación a esto último, algunos informantes hacen evidente "la pérdida" del uso de la lengua maya en el pueblo. Según indica el INEGI (2001) en su censo del 2000, la población hablante de lengua maya en Telchac Pueblo varía entre el 20 y el 29 por ciento; ${ }^{11}$ en su mayoría es "gente mayor", o sea, los padres, tíos o abuelos que la emplean para que los hijos no entiendan "la conversación de los adultos".

Asimismo, su detrimento se explica por el castigo que recibieron "los mayores" durante su estadía en la escuela para "evitar" la maya y privilegiar el castellano por considerar a éste último como símbolo de educación ("de estar educado"), además de concebirlo como "lo mejor o lo máximo" pues hablar maya es sinónimo de ignorancia, de "ser indio". Estas afirmaciones o presupuestos significan que la lengua maya equivale a alguna forma de "atraso" y, al parecer, esta ideología comenzó a operar a partir de la mitad del siglo pasado hasta

\footnotetext{
${ }^{8}$ De acuerdo con Macossay V. y Castillo B. (1986), la zona henequenera abarca 52 municipios de los 106 que conforman la entidad federativa; la extensión de aquella sería de $11190 \mathrm{~km}^{2}$, es decir, el 26 por ciento de la superficie total de la entidad. Mientras, para Baños Ramírez (1989) únicamente 58 municipios pertenecerían a esta zona con una superficie de $12951 \mathrm{~km}^{2}$, o sea, 32.4 por ciento de la totalidad del territorio yucateco.

${ }^{9}$ El hetzmek es un rito de paso o iniciación que integra al infante a la comunidad. La forma y los significados específicos se han transformado a través del tiempo y del espacio; sin embargo, sobrevive el propósito central de preparar al niño para que en el futuro sea un adulto de provecho (Fortuny Loret de Mola, 2004). [N. del E.: cf. Estudios de Cultura Maya, vol. 33.]

${ }^{10}$ La ceremonia del ch'a' cháak, por su significado cultural y religioso, está relacionada con la siembra del maíz realizada en comunidades milperas entre julio y agosto. Cf. Máas Collí, 1991; Quintal et al., 2003b.

${ }^{11}$ Los hablantes de lengua maya en Telchac Pueblo son 656 en total, es decir, cerca del 22 por ciento de la población de cinco años o más (INEGI, 2001).
} 


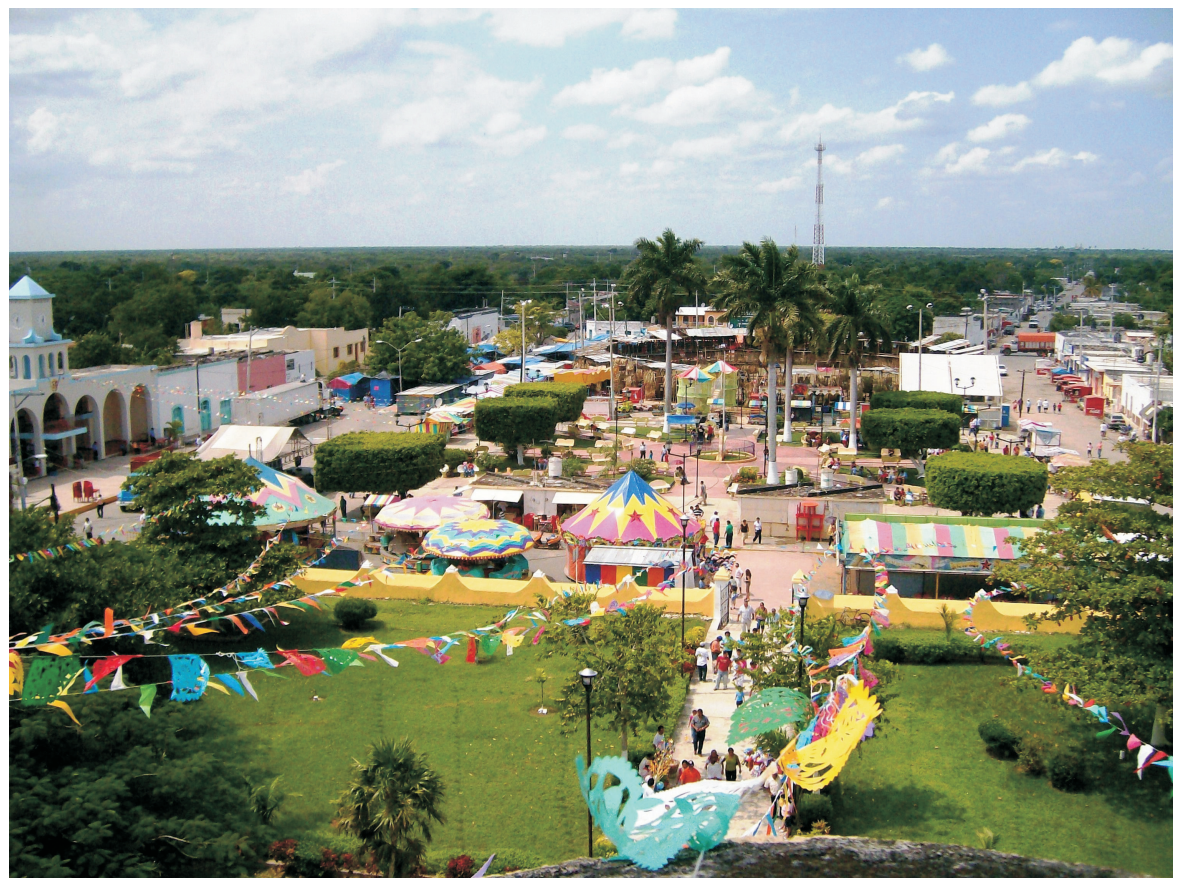

Figura 2. Plaza principal de Telchac Pueblo en el marco de la fiesta patronal. Foto del autor

su continuación en las posteriores décadas, cuando empezó a menguar. Estos informantes como muchos otros del pueblo aprendieron la lengua maya al "ver y escuchar" cómo se decía. Se carece de la capacidad de hablar completa y "correctamente" la lengua maya, pero es posible entender "algunas cosas", sobre todo entre ciertas personas con el interés de aprender la lengua ya sea al poner atención en las pláticas habituales entre los mayores o, en su defecto, al tomar algunos cursos en la capital del estado.

El devenir histórico en Telchac Pueblo constituye la base para continuar y conservar un lugar en el tiempo y el espacio, pues sirven de sustento para (re) crear nuevas formas de vida social y comunitaria. En ese sentido, los procesos de cambio y continuidad en la realidad yucateca han originado en sus habitantes un movimiento de reivindicación de sus particularidades y diversidades al cruzar, reinterpretar y resignificar elementos ajenos a sus experiencias e incorporarlos a su mundo social, cultural y simbólico (Bonfil Batalla, 1991). Un hecho de profundas transformaciones en la realidad yucateca es el conjunto de distintas visiones identitarias constantemente negociadas, reconstruidas e influenciadas por elementos nuevos de las culturas en contacto, principalmente las de carácter étnico-cultural. De ahí la importancia de reconocer de qué identidad o identidades estamos hablando, proceso que aquí presento de manera puntual. 


\section{Huellas de la identidad yucateca}

Para iniciar la discusión sobre la(s) identidad(es) de los yucatecos, o mejor dicho, "mayas" yucatecos, viene a colación una reflexión sobre la posibilidad de considerarlos una etnia o no. Ésta ha sido una discusión larga y tendida en donde los científicos sociales, los mayistas y yucatecólogos, tanto extranjeros como locales, no se ponen de acuerdo (Fallaw, 2004; Quintal Avilés, 2005; Mattiace, 2009). Hoy día existen antecedentes históricos desde donde se busca que los yucatecos, y quienes pretenden denominar a los habitantes de Yucatán como mayas yucatecos o simplemente mayas, intenten responder a una pregunta crucial en sus vidas: "usted, ¿se considera maya?". La identidad yucateca, como se quiere aquí (de)mostrar, está revestida de muchos significados construidos y adjudicados de forma auto o heteroimpuesta donde el sí mismo y la otredad (llámese Iglesia, Estado o gobierno, hasta pasar por los mismos antropólogos, arqueólogos e historiadores) buscan descifrar lo que se entiende y se refiere como elemento identitario en Yucatán al examinar las denominaciones del ser maya, mayero, mestizo, o maya yucateco.

Ante este panorama, las diversas interpretaciones (como veremos) están en continua interacción y confrontación con las asignaciones "generalizadas" que el Estado histórica y socialmente ha impuesto sobre sectores sociales subordinados. Por la multiplicidad de identificaciones que existen, es preciso diferenciar cada una según los aspectos históricos, políticos y/o sociales que se encarnan en la cotidianeidad de mujeres y hombres yucatecos. En primer lugar, al indagar sobre la identidad maya, particularmente sobre "los mayas", es común entre la población especificar a éstos como los constructores de los imponentes centros ceremoniales, sobre todo al resaltar "la apariencia enigmática de su escritura y [...] por no conocer una versión aceptable de la antigua función de sus ruinas [o pirámides]" (Gutiérrez Estévez, 1992: 425).

En cuanto a la lengua maya ${ }^{12}$ o maya' $\operatorname{t'}^{\prime} n^{13}$ como segundo aspecto definitorio, algunos habitantes "modernos" de la zona yucateca cuya lengua materna es la maya afirman que ésta era disímil a la de los primeros moradores, los llamados "mayas prehispánicos"; por ello ante la "nueva y diferente" maya que hablan se nombran como mayeros. Los actuales hablantes de la lengua maya o mayeros se definen por su asociación con otros elementos socioculturales como el municipio o la comisaría de procedencia (sea ésta monolinguie o no), así como por otras prác-

\footnotetext{
${ }^{12}$ Para los habitantes de la península de Yucatán, el idioma de esta región según Lilian Scheffler es "denominado por los especialistas Maya Peninsular y pertenece al grupo Maya-Totonaco, tronco Mayense, familia Mayense, subfamilia Yax, y a diferencia de lo que ocurre en otros sitios del país, el maya en Campeche y Yucatán no [es hablado] sólo [por] la población indígena sino también [por otros] habitantes quienes lo consideran como un elemento de prestigio, en cambio en Quintana Roo lo hablan únicamente los indígenas" (1992: 173).

${ }^{13}$ Este es el término para identificar la lengua indígena de Yucatán y a la que los lingüistas denominaron como maya en el siglo xix para referirse a una de las 31 lenguas mesoamericanas existentes (Gabbert, 2004).
} 
ticas rituales como la ceremonia del ch'a' cháak junto con la creencia mucho más generalizada en los aluxes, por citar algunos ejemplos. Con todo, actualmente la lengua es el criterio predilecto de clasificación étnica o, más bien, cultural, si bien Gutiérrez Estévez advierte que en la región mesoamericana resulta "excepcional que un término de pertenencia linguística sea utilizado socialmente como término de adscripción étnica" (1992: 423; énfasis mío).

Por tanto, resulta interesante este aspecto linguíístico como elemento identitario para una colectividad a pesar del señalamiento de este autor, pues la identificación comúnmente se produce con respecto a la comunidad local (soy de Peto, de Ucí, de Progreso, de Telchac Pueblo). Además de la de mayeros, una tercera noción corresponde a la de mestizo, la cual es muy distinta a la empleada en el resto del país por la trascendencia étnico-racial, histórica y política que encierra. Mestizo, en nuestro días, es la yucateca (o maya yucateca) que usa el hipil, y el varón habitante de poblaciones más pequeñas y aisladas que usa la ropa típica de mestizo (Castañeda, 2004). Por ello ser mestizo alude a la indumentaria tradicional. ${ }^{14}$ Asimismo, mestizo es el común denominador de identificación de lo que en otros lugares se podría considerar "indio" o "indígena" (Gutiérrez Estévez, 1992) a raíz del cruce racial y cultural ocurrido durante la época colonial hasta el siglo xix (Quintal Avilés, 2005).

Quintal Avilés argumenta que el surgimiento y reafirmación de la identidad mestiza tienen sus antecedentes en "la época revolucionaria y quizá, de manera más concreta, [con la política popular] de los gobiernos socialistas de Alvarado y Carrillo Puerto" (2005: 329). Salvador Alvarado, a pesar de apoyar las escuelas mayas, pretendió "borrar" la imagen de este grupo sobre todo en su indumentaria al prohibir "que los [hombres] mayas usaran el delantal de cotín característico de la vestimenta del maya yucateco [porque] le parecía afeminado" (Quintal Avilés, 2005: 330). Mientras, Felipe Carrillo Puerto apelaba por una "elevación del nivel de vida" de los mayas al volverlos "campesinos y obreros socialistas" (Quintal Avilés, 2005: 330). Pero la conceptualización va más allá pues abarcaría (o no) el hablar la lengua, llevar apellido maya (Can, Ek, Poot, Dzul) o continuar con las prácticas rituales y costumbres ancestrales como el hetzmek o la culinaria yucateca. En otros términos, no implica distanciamiento respecto a las raíces mayas prehispánicas (Mattiace, 2009).

En ese tenor, un cuarto plano identitario, la noción de indígena, se borra o se elimina a partir del levantamiento de la Guerra de Castas que inicia a mitad del siglo xix y termina a principios del siglo xx (1847-1902). ${ }^{15}$ La Guerra de Castas fue

\footnotetext{
${ }^{14}$ Las mujeres visten hipil blanco con adornos por lo general bordados en el cuello y en la parte inferior con flores de colores. Sobre los hombros llevan rebozo, calzan zapatos de tacón ancho y su cabello lo acomodan en forma de sorongo o t'uuch decorado con flores. Por su parte, el hombre usa guayabera y pantalón blancos, lleva sombrero de palma, calza alpargatas de cuero con tacón alto y de una de las bolsas del pantalón lleva colgado un paliacate o pañuelo colorado (Quintal Avilés, 2005).

${ }^{15}$ Gabbert (2004) refiere que este encuentro bélico continuó ya entrado el siglo xx (al menos durante las tres primeras décadas), cuando las nuevas generaciones de "rebeldes" aun se encontraban
} 
el evento que provocó la división radical de "los mayas" entre los "sublevados bravos" o macehuales (los mayas violentos del oriente quienes huyeron a las selvas del actual estado de Quintana Roo al terminar la guerra junto con aquellos que no fueron masacrados); y los otros, los mayas "controlados" o "pacíficos", quienes adoptaron los elementos del mestizo para diferenciarse del blanco yucateco pero también para diferenciarse del indígena (Gabbert, 2004). Con ello, la indianidad de estos últimos fue eliminada o bien subordina ante la élite dominante, de ahí que esta rebelión y sus consecuencias sea una de las explicaciones sobre la "costumbre" de llamar mestizo a la mayor parte de los habitantes de Yucatán (Quintal Avilés, 2005; Solís Lizama y Fortuny Loret de Mola, 2010).

Gabbert (2004) señala que la guerra no hizo posible el surgimiento de una conciencia étnica que abarcara a todas las fuerzas, "indios y no-indios", porque ambos bandos eran del mismo "territorio". Por tanto, difiere de la idea generalizada que sostiene que la guerra consistió en una confrontación étnico-racial. Este autor llega a una conclusión fundamental sobre la "etnógenesis maya” y que muy bien manifiesta Castañeda (2004: 16) al apuntar que ésta, "la etnogénesis de 'maya' como etnicidad y grupos étnicos fue una consecuencia de la Guerra de Castas, no su pre-condición ni su causa sustantiva”. ${ }^{16}$ Aun así, para comprender la etnicidad, no debe pensarse en ésta como una especie de "colectividades étnicas”, más bien en individuos que emplean "categorías étnicas en la interacción social" (Gabbert, 2004: 63).

El caso del blanco yucateco, ${ }^{17}$ como quinto aspecto, es parecido al del etnónimo de mestizo pues, además de que aleja a quienes lo ostentan de "los otros", los mismos no se consideran indígenas ni tampoco mayas. De ahí que la noción de indígena y la de maya desaparezcan en la de blanco pues ésta adopta toda una serie de propiedades del mestizo o de lo que debería ser el indígena, en el sentido de que el blanco yucateco se apropia, presta o intercambia ciertos elementos o prácticas culturales como es el caso de la lengua maya, el vestido maya contemporáneo o la cocina regional (cuyo resultado es una combinación de

fuera del control e influencias por parte del gobierno mexicano. Los líderes más representativos del movimiento fueron los caciques Manuel Antonio Ay de Chichimilá, Cecilio Chi de Tepich y Jacinto Pat de Tihosuco.

${ }^{16}$ Esta carencia de conciencia étnica o etnicidad ausente no hizo posible marcar los límites con respecto a los grupos de poder o el Estado mismo. Por tanto, a consecuencia del nuevo estatus social (no ser indígenas) y los privilegios e incentivos supuestamente recibidos (por ejemplo, la liquidación de sus deudas con las tiendas de raya), se generó una relación de dependencia y sumisión presente hasta nuestros días. Los trabajos de Castañeda (2004), Quintal Avilés (2005), Mattiace (2009), así como el de Solís Lizama y Fortuny Loret de Mola (2010) son algunos referentes donde se desarrollan más estas ideas.

${ }^{17}$ En una de las notas de su artículo, Gabbert (2004: 78) apunta que en Yucatán, de acuerdo con Eligio Ancona (1978), "el nombre de blancos [no sólo incluye] a los que conservan pura en sus venas la sangre europea, sino hasta aquéllos que la llevan mezclada en cualquier cantidad con la indígena. [Por ello] los indios [...] son los descendientes de los mayas que no han mezclado su sangre con ninguna otra, y los [blancos son] los individuos de todas las demás razas". 
alimentos yucatecos tradicionales y productos europeos, sobre todo las especias que trajeron los españoles).

De hecho, el mismo lenguaje yucateco no es el español hablado en el resto de México, más bien es un castellano "mayanizado" con un acento característico (estacato) y en el cual se intercalan algunas palabras en maya. Tales modismos en el lenguaje cotidiano son comprensibles por quienes habitan el estado, a tal grado que a cierta edad se percatan del español hablado cuyo resultado no es más que una mezcla del castellano con la lengua maya. Otro punto de análisis lo encontramos inclusive en el vestido. Desde mediados del siglo xix la clase alta, los blancos, no solamente hablaban perfecta y completamente bien el maya, sino que además se apropiaron y reprodujeron el vestido de "los mayas" (Millet Cámara y Quintal Avilés, 1994). Pero ni por equivocación se concebían como tales.

Aquí es importante atender que en el caso del blanco yucateco, éste pudo ser un concepto identitario entre las antiguas familias de élite pero en la actualidad no puede ser utilizado como característica de autoidentificación ya que:

[...] se ha vuelto un término fallido [que se usó] para referirse a las relaciones étnico-raciales de los siglos anteriores y por los antropólogos como un marcador rápido y fácil para identificar a los no-mayas, no-criollos, no-mestizos, no-mayeros, pueblos y sociedad yucatecos urbanos o rurales (Castañeda, 2004: 19).

Como vemos, histórica y socialmente se ha originado un intercambio de elementos culturales que han borrado estas diferencias (Restall, 2004) o difuminado ciertas expresiones identitarias que al presente complican el afirmar con certeza quién es maya y quién no, quién es mestizo y quién no. Inclusive la ubicación geográfica es un atributo central para considerar esta multiplicidad de representaciones en la entidad (Mattiace, 2009). Empero, a lo largo de este aparatado, ha sido posible discernir que la(s) identidad(es) en Yucatán se basan "en criterios que [atraviesan la] clase, género, y lenguaje, más no la etnicidad [como tal]" (Castañeda, 2004: 19). Y con respecto a los mestizos, aunque esta noción pueda traslaparse con la de indígena, va más allá pues a pesar de hablar la lengua, continuar con la práctica de ciertos rituales o vestir a la usanza maya, probablemente muchos mestizos carezcan de alguna o de todas estas cualidades, lo que hace aun más compleja la identificación.

Asimismo, esta caracterización "étnica" es relativamente nueva entre los estudiosos de lo yucateco pues fue un tanto impuesta por los antropólogos, los arqueólogos y también recientemente por el mismo Estado a través de un organismo implementado bajo la primera gubernatura panista de Patricio Patrón Laviada (2001-2007). Ha sido el Instituto para el Desarrollo de la Cultura Maya de Yucatán (Indemaya) con el lanzamiento del programa way yano'one' (en castellano se traduce "aquí estamos"), el que impulsó el membrete de "mayas". Pero si se nombra mayas a los yucatecos entonces, ¿cómo podrían distinguirse de los mayas de Chiapas o Guatemala? Desde luego la península de Yucatán es un caso 
único en el sentido de que es una región bastante extensa con casi un millón y medio de indígenas o habitantes que emplean la misma lengua con algunas variaciones (CDI, 2006). Es un suceso notable en el país que en un área geográfica tan amplia se hable el mismo lenguaje allende al castellano; eso ha permitido la permanencia de la lengua maya a pesar de la influencia dominante del español. ${ }^{18}$

Es un hecho que la identidad yucateca es, y ha sido, una construcción social basada en el contraste y la diferenciación (desde la imposición colonial pasando por la académica) y aun así admite contar con identidades multifacéticas y escapar de categorizaciones exclusivas basadas en términos de oposición binaria (Restall, 2004). Y aun con la puesta en marcha del nacionalismo cultural del Estado, en Yucatán la(s) identidad(es) no emergieron con base en un terreno cultural de identificación unificada y mucho menos étnica (Fallaw, 2004). De ahí la tarea de distinguir y evidenciar bajo qué circunstancias se perpetúa, modifica o descarta algún elemento de esta multidentidad y en ese sentido señalar, discutir, analizar y reconstruir el estudio de un contexto nuevo con una tradición centenaria en el país: la migración internacional yucateca.

\section{Discursos y prácticas situados en una comunidad migrante}

Los sujetos (individuales o colectivos), como señala Giménez (2007), se definen a sí mismos a partir de los eventos y circunstancias en los cuales se encuentran; con ellos escogen, determinan e incorporan de manera subjetiva sus particularidades para luego expresarlas en sus múltiples discursos y prácticas sociales que los definen y caracterizan. Los espacios de identificación, sean estos laborales, familiares, territoriales, de género o étnicos, entre otros, adquieren otro (o nuevo) significado al surgir en contextos específicos bajo formas alternativas gracias a sus "prácticas situadas" (Okamura, 1981; O’Connor, 1989; Brennies, 1994; Rampton, 1995, Guarnizo y Smith, 1999). Una conceptualización de la identidad considerada como "situada" o "situacional" será de mucha relevancia en este estudio.

Por "identidades situadas" se entiende el conjunto de representaciones y prácticas culturales dentro de contextos y situaciones concretos y en donde las personas tiene distintos recursos disponibles; entre ellos, la posibilidad de no expresar "abiertamente" su identidad o de "neutralizarla" frente a los demás sí es que ellos lo juzgan conveniente. Esto no quiere decir que la identidad es superficial o cambiante, sino que las formas y representaciones de ella no son nece-

18 Según datos de la Comisión Nacional para el Desarrollo de los Pueblos Indígenas, CDI (2006), en el 2000 el estado de Yucatán contaba con una población total de 1635361 habitantes. De ellos, cerca del 60 por ciento corresponde a población indígena cuya lengua principal es la maya: un total de 967943, siendo el grupo etnolinguiístico más importante de la región y el segundo más grande del país. 
sariamente obviadas de forma intencional ni todo el tiempo. Es más, un pueblo marginado puede elegir "esconder" estos símbolos como un mecanismo de sobrevivencia ante la sociedad dominante y hegemónica. Esta es la situación de los telchaqueños con respecto a la lengua maya, como se ha mencionado y se discutirá más adelante, o el caso descrito por Moctezuma Zamarrón (2001) de los indígenas mayos de Sonora en que una misma persona, dentro del contexto de una fiesta tradicional, puede sentirse completamente indígena, pero "anular" o "contrarrestar" dicha identidad en el ámbito escolar o laboral.

Así, lo "situacional" es tratado por Donald L. Brennies (1994) al señalar que la identidad de las personas depende de las circunstancias que lo rodean y es desde ahí donde ellos deciden, escogen ponerla sobre la mesa de manera particular o bien, si deciden hacerlo vía el discurso, prefieren incluir o excluir a otros actores sociales. En ese sentido, la posibilidad de que cada actor social pueda en un momento dado neutralizar su identidad en un entorno desfavorable indica la naturaleza situacional de aquella. En el caso de migrantes internacionales, la clase social, el género, la edad y la etnia son, en definitiva, otras divisiones que agrupan personas dentro de una misma sociedad matizada de diversos discursos y prácticas que incluyen o excluyen. ${ }^{19}$ Por ello hay todo tipo de formas de excluirincluir y, por tanto, identidad(es) situada(s).

Como señala Ben Rampton cuando dice:

[...] se ve que etnicidad, clase social y género como otras identidades son relevantes de acuerdo a contextos y situaciones sociales específicas según las necesidades y presiones. Una de las implicaciones importantes de esta perspectiva es: las identidades no son fijas, sino negociadas, adquiriendo significado en cuanto son activadas dentro de interacciones sociales específicas (1995: 486; la traducción es mía).

Con base en esta diversidad de planteamientos sobre la construcción de identidades en una multiplicidad de escenarios (lugar de origen, lugar de destino y transnacionalmente), se pueden resaltar los cambios y continuidades que los migrantes mexicanos realizan desde el contexto sociocultural donde se hallen. Esta discusión será la vía de abordaje para documentar las dimensiones o elementos culturales que definen a los telchaqueños a partir de sus prácticas cotidianas y para apreciar las múltiples concepciones sobre el sí mismo con respecto a la otredad.

Una identidad central entre los migrantes es la que construyen en relación con el pueblo. El terruño es el espacio por excelencia donde se demuestra tanto el lugar de procedencia como una poderosa nostalgia por lo dejado; con ello surge un fuerte sentido de pertenencia en los recuerdos de "sus ausentes" cuando le otorgan al terruño diferentes significados. Las frases repetidas entre ellos "soy

${ }^{19}$ Claudia Jean Harriss Clare, doctora en ciencias del lenguaje y profesora-investigadora de la Escuela Nacional de Antropología e Historia, Unidad Chihuahua. Comunicación personal el 11 de diciembre del 2008. 
de Yucatán, soy yucateco(a), soy telchaqueño(a), nací, crecí, viví o vivo en Telchac, mi pueblo", expresan un poderoso sentido de pertenencia:

Yo soy yucateco, yucateco de Telchac [Pueblo], viviendo en Oxnard pero yucateco de Telchac [...] (Miguel, indocumentado, entrevista realizada en Oxnard el 30 de junio del 2008).

Yo me considero yucateca [y] mi pueblo significa mi pueblo, mi pueblo querido que voy y trato en ir a visitarlo cada año... porque voy y visito a la gente que quiero [...] (Claudia, ciudadana, entrevista realizada en Oxnard el 23 de junio del 2008).

[...] no hay como estar en un pueblo, [ahí] estás caminando en las calles... a las seis de la tarde [puedes tomar] un baño, si no ves telenovelas, jalas una silla y te sientas a la puerta de tu casa o puedes ir al parque... me gusta más mi pueblo a pesar que tengo [más de] 30 años aquí (Alberto, ciudadano, entrevista realizada en Oxnard el 29 de junio del 2007).

El pueblo es bonito, a mi me gusta, me encanta, pero así como para ir a pasear porque uno ya buscó [en Oxnard] el modo de vivir. Yo no podría irme al pueblo a vivir porque voy a estar solita [...] y para estar solita mejor vivo aquí (Alicia, ciudadana, entrevista realizada en Oxnard el 30 de julio del 2008).

Yo soy yucateco, es mi pueblo, porto esa sangre, es mi identidad [...] (Pablo, indocumentado, entrevista realizada en Oxnard el 2 de julio del 2008).

La presencia del pueblo originario en sus vidas y memoria los vincula de tal suerte que la lejanía o distancia no significan una ruptura o abandono del territorio o, en palabras de Giménez (2007: 126):

[...] la ‘desterritorialización' física no implica automáticamente la desterritorialización en términos simbólicos y subjetivos. Se puede abandonar físicamente un territorio, sin perder la referencia simbólica y subjetiva al mismo a través de la comunicación a distancia, la memoria, el recuerdo y la nostalgia.

Dejar el terruño para estos yucatecos implica "llevárselo en la maleta" a través de sus productos, especias, galletas, fotos, videos, entre otros (Boruchoff, 1999; Díaz Gómez, 2002). Además, siempre buscan el modo de retornar a la matria como ya ocurrió con la mayoría de los braceros, en un futuro. Los actuales migrantes, después de concluida su labor de padres y proveedores, comentan:

[Yo extrañaba] a mi pueblo y a mi familia, porque ahí [en Telchac] están mis raíces, la costumbre y todo. [Yo decía] que el día que me pase algo, que me traigan aquí [al pueblo...] una enfermedad, una muerte, un accidente, algo, porque aquí nací [...por eso decidí regresar] (Braulio, residente, entrevista realizada en Telchac Pueblo el 20 de enero del 2008).

[...] como le digo, yo pertenezco allá. Yo siempre he querido morir allá, no importa que yo esté aquí [en Oxnard], ya cuando mis hijos hagan su vida y cuando puedan valerse por sí 
mismos, si yo tengo la oportunidad de morirme en mi pueblito me iría, yo los dejo [aquí] y que me vayan a visitar [...] (Miguel, indocumentado, entrevista realizada en Oxnard el 30 de junio del 2008).

El testimonio de Braulio y Miguel expresan la esperanza y el deseo de muchos telchaqueños que se beneficiaron con la IRCA (Inmigration Reform and Control Act) e incluso de aquellos que llegaron después de la amnistía de 1986. Asimismo, es interesante lo que Miguel nos menciona en su papel de padre al referirse a los hijos, quienes "podrían visitarlo al pueblo"; si bien, al mismo tiempo discute las implicaciones para las nuevas generaciones de nacer y vivir "del otro lado", como lo afirma don Alberto (ciudadano con poco más de treinta y cinco años radicando en Oxnard) al señalar lo difícil que sería para sus hijas nacidas "allá" vivir en el pueblo debido a las distintas costumbres. Todo esto se debe a los elementos sociales y culturales que se experimentan en dos naciones distintas y que, no obstante, cohabitan (Espinosa, 1998; Suárez-Orozco y Suárez-Orozco, 2003).

Como vemos, el sentido de pertenencia al pueblo ("soy de Telchac") es consistente entre los migrantes, pero no así el uso de ciertos elementos identitarios considerados como prácticas cotidianas. Así sucede con el uso de la lengua maya o del vestido de mujer llamado hipil, de empleo cotidiano, o el de gala denominado terno y la mayoría de las veces portado en el marco de la fiesta patronal (Millet Cámara y Quintal Avilés, 1994; Quintal Avilés, 2005). Estos elementos son temas de reflexión entre los lugareños del pueblo y "los ausentes" que nos llevan a comprender al municipio a partir de los diversos procesos sociohistóricos que han moldeado la región ex henequenera; también revela en Telchac Pueblo, como en otros municipios que conforman la zona, una menor vinculación a la cultura maya ancestral. Destaca el caso de la lengua materna:

No hablo la maya pero si la entiendo... algunas palabritas nada más pero no me puedo comunicar por medio de la [lengua] con otra persona que lo hable, no puedo pero si entiendo las palabras, lo que significan. [Aquí en el pueblo muy poca gente la habla,] creo que como un 20 por ciento. Puede ser por la preparación de las escuelas [para aprender en castellano y también porque] a veces los papás no inculcan a los muchachos para que hablen la maya, porque la maya es un idioma [...y] es muy importante para nuestro medio yucateco porque con eso nos identificamos... es muy importante que se hable, que no se pierda... los mayahablantes de aquí [de Telchac] no se comparan con otras comunidades de Yucatán [...] donde casi eso hablan. Por ejemplo allá por Tizimín, Valladolid, por el cono sur, allá por Tekax, Peto... en todos esos lugares hay comunidades donde pura maya hablan (Augusto, retornado, entrevista realizada en Telchac Pueblo el 29 de enero del 2008).

[No hablamos la maya por] nuestra propia gente... o por vergüenza o por marginación porque mucha gente se burla de nuestro acento, yo pienso que sienten vergüenza incluso a enseñar el idioma que es de nuestra cultura y pienso que mucho de eso influye en la educación que tus padres tienen. Nunca fui enseñado y a veces me siento avergonzado [...] soy de [Yucatán] pero no puedo decir que hablo [la maya] (Pablo, indocumentado, entrevista realizada en Oxnard el 2 de julio del 2008). 
El análisis ilustrativo que ofrecen estos yucatecos, particularmente en la reflexión de Pablo, evidencia el cambio cultural en Telchac relacionado con la lengua maya y resultado del estigma entre los mayahablantes que aprendieron a ocultarlo o a rechazarlo; además existen otros elementos que les ayudan a marcar la relativa distancia con su pasado maya, no obstante su importancia como referente identitario para los yucatecos como lo sugiere Augusto. La negación de la lengua, producto de la educación formal y el descrédito interiorizado para hablarla, son algunas explicaciones a las cuales se enfrentan incluso los no mayeros (quienes no conocen y/o practican la maya) a causa del acento característico como se expuso en el apartado anterior. Eso no significa que las leyendas o mitos que persisten en la herencia maya yucateca no sean conocidos por algunos lugareños, a lo cual contribuye la proximidad con otros municipios, por ejemplo Motul, donde historias sobre los aluxes o de Juan Tul, el dueño y señor del ganado, son temas de conversación.

En cuanto a la cocina yucateca, ésta forma parte de una buena parte de las recreaciones culturales en el vecino país del norte. La culinaria regional es el escenario por excelencia para fortalecer las redes familiares o de paisanaje, y uno de los momentos y espacios privilegiados para alimentar el orgullo por la identidad y la cercanía simbólica con el pueblo. Su elaboración y consumo implican intensos tiempos y espacios emocionales y sociales que conforman una parte de la memoria histórica de las pertenencias y costumbres que hasta hoy día permean la vida cotidiana de los "verdaderos" yucatecos. En el momento de la comida se reflejan las añoranzas por el pueblo, por la familia y por todo lo que ahí dejaron; al mismo tiempo, se abriga la esperanza de volver a estar en su pueblo. Así, el compartir la mesa es el mejor pretexto para llevar al cabo una reunión, acercarse a las propias raíces y trasmitirlas a las generaciones venideras bajo un escenario de múltiples matices.

Ese espacio que nos recuerde el terruño siempre se persigue, como lo demuestran doña Alicia Hernández y Claudia Chablé. En casa de doña Alicia, paisana de 68 años quien desde la década de 1990 se encuentra en Oxnard, siempre se procura cocinar comida yucateca, desde frijol con puerco hasta algún caldo de albóndigas, aunque consumen en gran medida productos del mar. La familia es grande, así que se preparan dos o más platillos para disfrutarlos en compañía. Se intenta comer siempre juntos cuando se puede; o bien, cuando llegan "los trabajadores" se les sirve y en ese instante inician las bromas y las risas que van aminorando el cansancio junto a los recuerdos de amigos, conocidos y situaciones que recuerdan al pueblo y hacen divertido el momento. Con doña Alicia y sus guisos, el buen humor nunca falta en su casa.

Lo mismo sucede con Claudia, una chica telchaqueña de 33 años quien prácticamente ha hecho toda su vida en Oxnard, pues a los 10 años dejó el pueblo. En su casa, invariablemente se almuerza en familia, poco antes de las tres de la tarde cuando su papá se dirige al trabajo. Resulta interesante lo que ocurre entre ellos pues su papá, don Carlos Chablé, y Alicia, su cuñada, son quienes cocinan y se encargan de preparar guisos típicos de Yucatán. Se trata de aprovechar ese momento familiar aunque ocurre lo mismo si hay invitados. Esa fue la experiencia 
de un día sábado cuando Claudia me invitó a comer en compañía de Ashanty, amiga del trabajo de origen afroamericano. Ante esta "mesa multicultural", el menú yucateco coronó el momento: desde polcanes, ${ }^{20}$ pasando por los kibis, ${ }^{21}$ panuchos y salbutes ${ }^{22}$ acompañados de una coca-cola o refrescos de sabor.

En aquella ocasión acompañé a Claudia al domicilio de otros paisanos telchaqueños, quienes hacen su venta de antojitos regionales yucatecos casi siempre los sábados; a dicha casa gente del pueblo como de otros lugares de Yucatán se dirige para hacer sus pedidos. La venta de comida ofrece panuchos, salbutes, kibis y polcanes, hasta encargos especiales de platillos más elaborados como el queso relleno, ${ }^{23}$ por ejemplo. Cada salbute o panucho se vende a un dólar y aun-

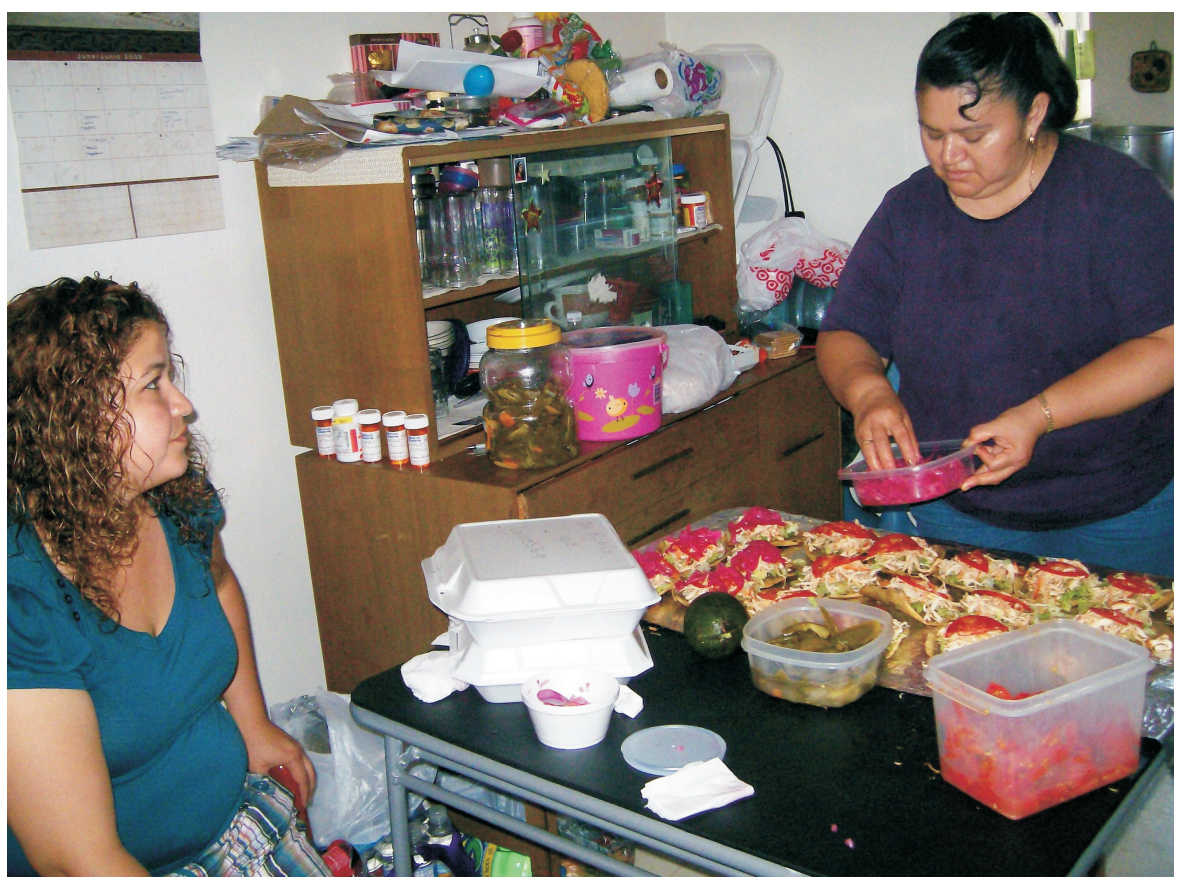

Figura 3. Venta de antojitos regionales en Oxnard.

En esa ocasión cada salbute valía un dólar. Foto del autor

${ }^{20}$ Los polcanes están hechos con masa de maíz, ibes tiernos, pepita molida y manteca de cerdo. Se prepara la masa de tal suerte que se forman "bolitas", las cuales se fríen en aceite.

21 Tomado de la comida libanesa, los kibis se hacen con harina de trigo acompañado con carne de cerdo (o de res si se prefiere), cebolla y orégano.

22 Estos antojitos son similares pues ambos se hacen con masa de maíz para formar las tortillas que se fríen en aceite para luego cubrirlo con carne de pavo o pollo deshebrado además de lechuga, tomate, cebolla curtida y aguacate, acompañado con chile jalapeño. La única diferencia radica en el frijol refrito con que se rellena el panucho, no así el salbute.

${ }^{23}$ Se elabora con carnes de res y cerdo molidas, aceitunas y alcaparras, tomates y un queso de bola. A éste último se le escarba hasta formar una cuenca que se rellena con los demás ingredientes. 
que resulte un poco caro comparado con los precios en los mercados y fondas en el lugar de origen, valen la pena. A fin de cuentas, el "ir a comprar panuchos" es el escenario perfecto para reencontrarse, saludarse y preguntar por la familia. Los lazos originados en el pueblo se llevan en el destino, donde se saludan los compadres, los conocidos, los cuates.

Por último, uno de los aspectos centrales relacionados con la identidad y el cambio cultural entre los migrantes telchaqueños no surgió de forma espontánea; más bien los sujetos sociales respondieron a interrogantes tales como: ¿usted cómo se identifica? ¿Se considera mexicano, yucateco, telchaqueño, maya? De ahí el siguiente caso único que vamos a tratar a continuación. La dificultad de discutir el tema de la etnicidad en Yucatán, como se ha mencionado en la sección anterior, pone en marcha otros elementos definitorios que cruzan y ponen en primer plano su(s) identidad(es), como lo menciona Castañeda (2004). Además se debe considerar la plasticidad del contexto social donde se ubiquen pues permite que los elementos étnicos, en este caso el "ser maya", se encubran o se reafirmen como lo explica Okamura (1981). Empero, la señora Cecilia a partir de “confusiones raciales" (re)crea su identidad maya:

[...] yo siempre he dicho que soy india maya... una maestra de la escuela me decía que si era china pues tenía rasgos asiáticos pero yo decía [que soy] de la cultura maya [...] muchas veces me preguntan: "ieres filipina?". "No, no soy filipina, soy mexicana”, respondo, y me dice mi esposo: "tú no les contestes, deja que ellos piensen lo que quieran". "No, yo soy india maya", le digo. [Cuando me operaron, una chica de origen asiático entró al cuarto y empezó hablarme en otro idiomal y no le entendía. iMe estaba hablando en tagalo porque pensó que era filipina! En una pastelería [donde siempre encargo algún postre,] quien atiende es una japonesa y me dice: ["tu eres la] 'mexicana japonesa'”, [y digo: "sí"] porque tengo la suerte de tener mis ojos rasgados [y] que me parezco a otras razas [...] (ciudadana, entrevista realizada en Telchac Pueblo el 5 de octubre del 2008; énfasis mío).

Es interesante observar cómo lo étnico se ha reinventado en la señora Cecilia (con casi cinco décadas de radicar con su esposo y familia en la Unión Americana) al denominarse "india" cuando el término indio, apelativo que cambió de significado por su connotación peyorativa a la expresión de indígena, ha caído en desuso en Yucatán mientras en ciertas regiones del país su carga despectiva y discriminante sigue operando, tal como sucede con los indígenas del sur al dirigirse al norte del país donde reinventan y "sitúan" su identidad étnica (López y Runsten, 2004). Aun así, el ejemplo es emblemático al indicar que hablamos y existimos en culturas vivas, dinámicas y cambiantes, tal como ocurre en la cultura maya yucateca donde es posible coexistir con todo aquello que representa al individuo más allá del terruño, al estar en una sociedad ajena y diferente de la que se proviene. En definitiva, cada una de estas identidades es producto de experiencias situadas en momentos y espacios específicos; dichas vivencias sirven como bisagras para ir y venir de una u otra identidad donde alguna de 
ellas será la que se ubique en un primer plano. Son, en palabras de Guarnizo y Smith (1999), los “yos” situados en y desde la interacción.

\section{A manera de conclusión}

El estudio de la(s) identidad(es) nos descubre la complejidad de los procesos sociales donde se encuentran e interactúan las personas. Al conjuntar diversas experiencias, el proceso identitario implica una constante referencia hacia el propio grupo producto del imaginario que le sostiene y, al mismo tiempo, una distinción-confrontación con respecto al otro para generar la cohesión social. Por ende, el cúmulo de adscripciones se construye siempre con relación a otras identidades y a partir de planos diferenciados como el género, la etnia, la región o lo generacional. Ahí se define uno vinculado con espacios y contextos específicos, los cuales otorgan particularidad a nuestras identificaciones respecto a la familia, el pueblo, la lengua o la nación. La clave reside en esa persistente voluntad de clarificación y conservación de los saberes propios capaces de otorgar sentido tanto en lo individual como en lo comunitario.

Como sistema de información en el individuo, la identidad busca siempre su especificidad y originalidad en su propia necesidad de expresarse y difundirse. De ahí que la producción de significados se interprete en ese incesante ir y venir entre diversas prácticas sociales en el marco de las relaciones de poder. Las dimensiones o prácticas culturales descritas entre los migrantes telchaqueños son reflejo de esa diversidad de ser y/o sentirse de Yucatán. Cada una de aquellas, desde los contextos donde se exponen, nos permite comprender su conformación social, cultural, política e histórica, todo ello desde una perspectiva situacional. Se construyen, pues, como evidencias sociales en las cuales se materializan sus pertenencias y es ahí, en ese tiempo-espacio, donde la persona elige y determina poner al frente, o bien ocultar, algún matiz de su identidad.

En primera instancia, los hechos históricos son un hito importante para explicar el ser maya en Yucatán al comprobar la influencia de la época colonial (aún presente hasta nuestros días bajo la llamada colonialidad como una prolongación de las formas de dominación novohispanas) en la vida de los yucatecos. El devenir histórico nos ofrece la pauta para distinguir los antecedentes y sus estructuras más profundas con el fin de preguntarnos el porqué algunas prácticas continúan y otras se diluyen, además de permitirnos observar de manera más amplia los aspectos sociohistóricos locales con base en procesos más amplios. Sin duda, el etnónimo de mestizo contiene relevantes implicaciones sobre su "uso" en gran parte del estado como lo refieren algunos estudios, cuya tarea se ha enfocado en entender esta identificación impuesta desde la Guerra de Castas e igualmente por los gobiernos de Salvador Alvarado y Felipe Carrillo Puerto, entre otros elementos señalados.

En tal sentido, la discusión sobre el distanciamiento del pasado cultural maya en Telchac Pueblo resulta central para poner en juego las representaciones sobre 
el sí mismo en estos migrantes yucatecos. Si bien el territorio es fundamental para fomentar la cohesión grupal, el uso de la lengua maya se encuentra en detrimento entre los pobladores y, por tanto, deja de ser un marcador de clasificación étnica como se afirma. Empero, entre los migrantes empieza a generarse un cuestionamiento sobre esta "pérdida" de la lengua al reconocer la dominación y subyugación a la que estuvieron sujetos por el sistema educativo principalmente. Quizá esto nos lleve a un proceso de reelaboración de lo maya conjuntamente con la persistencia de otros componentes socioculturales como la culinaria regional yucateca, que continúa realizándose más allá de esta región peninsular.

Sin duda esto se materializa en la reinvención étnica que aquella mujer telchaqueña (doña Cecilia) realiza al considerarse a sí misma como "india maya" y, con ello, nos abre el panorama para concebir a la etnicidad como transformadora de la realidad al conceder a sus conciudadanos la capacidad de asumir y/o encubrir ciertas cualidades sobre su identidad maya. Asimismo, nos permite advertir los discursos hegemónicos que operan desde el aparato de poder (instancias gubernamentales) para imponer o eliminar aquello de "lo maya" que, según sus necesidades e intereses, le conviene resaltar o esconder. Esta franca desventaja, producto de la subordinación a la supremacía hegemónica debida al colonialismo (es decir, a los blancos yucatecos y a los hacendados), ha borrado algunos marcadores distintivos. Pero en este juego, el grupo dominante ha adquirido y asumido elementos característicos de la cultura maya a tal punto que se ha creado una imagen prístina, mágica y enigmática para ser proyectada ante el mundo.

A lo largo de este artículo he mostrado la pertinencia de la identidad situada o situacional entre los migrantes telchaqueños en Estados Unidos. Según este planteamiento el individuo cuenta con la facultad de elaborar sus particularidades a partir de sus discursos y prácticas sociales. La capacidad de innovación a través de ciertos elementos culturales como la etnicidad nos refiere a nuevas rutas más allá de aquellas que abogan por una "conservación" cultural. La importancia de esto reside en la voluntad de seguir siendo: por ello nuestra función es entender dichos procesos en conjunto con quienes los experimentan. En definitiva, la identidad es una práctica, una forma de vivir que no necesariamente conlleva una denominación indígena en la mayoría de los habitantes de Yucatán, pero responde a patrones culturales étnicos (el ser maya) declarado en sus guisos, en su vestimenta e incluso hasta en su forma característica de hablar.

\section{BIBLIOGRAFÍA}

Baños Ramírez, Othón

1989 Yucatán: ejidos sin campesinos. Mérida: Universidad Autónoma de Yucatán.

Bartolomé, Miguel Alberto

2004 Gente de costumbre y gente de razón. Las identidades étnicas en México, 2aa ed. México: Siglo XXI. 
Be Ramírez, Pedro Antonio

2010 "Caminantes del Mayab: construcción de identidades entre migrantes de Telchac Pueblo, Yucatán/Oxnard, Ventura, California”, tesis de maestría en Antropología Social. Chihuahua: Escuela Nacional de Antropología e Historia, Unidad Chihuahua / Centro de Investigaciones y Estudios Superiores en Antropología Social.

Bonfil Batalla, Guillermo

1991 Pensar nuestra cultura. México: Alianza Editorial.

Boruchoff, Judith A.

1999 "Equipaje cultural: objetos, identidad y transnacionalismo en Guerrero y Chicago", Gail Mummert (ed.). México: El Colegio de Michoacán / Centro de Investigación y Desarrollo del Estado de Michoacán, 499-518.

Brennies, Donald L.

1994 "Foreword", Situated meaning: inside and outside in Japanese self, society, and language, Jane M. Bachnik y Charles J. Quinn, Jr. (eds.). Princeton: Princeton University Press, ix-xii.

Castañeda, Quetzil E.

1995 "La economía 'escritural' y la invención de las culturas mayas en el 'museo' de Chichén Itza”, Revista Española de Antropología Americana, 25: 181-203. Madrid: Universidad Complutense.

2004 “'iNo somos indígenas!' Una introducción a la identidad maya de Yucatán”, Estrategias identitarias. Educación y la antropología histórica en Yucatán, Juan A. Castillo Cocom y Quetzil E. Castañeda (eds.). Mérida: Universidad Pedagógica Nacional-Mérida / The Open School of Ethnography and Anthropology / Secretaría de Educación Pública, 1-32.

Comisión Nacional para el Desarrollo de los Pueblos Indígenas (CDI)

2006 Regiones indígenas de México. México: Comisión Nacional para el Desarrollo de los Pueblos Indígenas / Programa de las Naciones Unidas para el Desarrollo.

Díaz Gómez, Leticia

2002 "Siguiendo los pasos hacia Estados Unidos. Interacción infantil con videos, cartas y fotografías", Migración internacional e identidades cambiantes, María Eugenia Anguiano Téllez y Miguel J. Hernández Madrid (eds.). Zamora: El Colegio de Michoacán / El Colegio de la Frontera Norte, 229-250.

Espinosa, Víctor M.

1998 El dilema del retorno. Migración, género y pertenencia en un contexto transnacional. Zamora: El Colegio de Michoacán / El Colegio de Jalisco.

Fallaw, Ben

2004 "Repensando la resistencia maya: cambios en las relaciones entre los maestros federales y las comunidades mayas en el Oriente, 1929-1935", Estrategias identitarias. Educación y la antropología histórica en Yucatán, Juan A. 
Castillo Cocom y Quetzil E. Castañeda (eds.). Mérida: Universidad Pedagógica Nacional-Mérida / The Open School of Ethnography and Anthropology / Secretaría de Educación Pública, 91-119.

Fortuny Loret de Mola, Patricia

2004 "Transnational hetzmek: entre Oxkutzcab y San Pancho", Estrategias identitarias. Educación y la antropología histórica en Yucatán, Juan A. Castillo Cocom y Quetzil E. Castañeda (eds.). Mérida: Universidad Pedagógica NacionalMérida / The Open School of Ethnography and Anthropology / Secretaría de Educación Pública, 225-254.

Gabbert, Wolfgang

2004 "Sobre amigos y enemigos: la Guerra de Castas y la etnicidad en Yucatán”, Estrategias identitarias. Educación y la antropología histórica en Yucatán, Juan A. Castillo Cocom y Quetzil E. Castañeda (eds.). Mérida: Universidad Pedagógica Nacional-Mérida / The Open School of Ethnography and Anthropology / Secretaría de Educación Pública, 61-90.

Giménez, Gilberto

2007 Estudios sobre la cultura y las identidades sociales. México: Consejo Nacional para la Cultura y las Artes / Instituto Tecnológico y de Estudios Superiores de Occidente.

Guarnizo, Luis Eduardo y Michael Peter Smith

1999 "Las localizaciones del transnacionalismo", Fronteras fragmentadas, Gail Mummert (ed.). México: Colegio de Michoacán / Centro de Investigación y Desarrollo del Estado de Michoacán, 87-112.

Gutiérrez Estévez, Manuel

1992 “Mayas y 'Mayeros': los antepasados como otros”, De palabra y obra en el nuevo mundo. Imágines interétnicas, vol. 1, Miguel León-Portilla, Manuel Gutiérrez Estévez, Gary H. Gossen y J. Jorge Klor de Alva (eds.). Madrid: Siglo XXI, 417-442.

Guzmán Medina, María Guadalupe Violeta

2005 Una nueva mirada hacia los mayas de Yucatán. Identidad, cultura y poder. Mérida: Universidad Autónoma de Yucatán.

Instituto Nacional de Estadística, Geografía e Informática

2001 XII Censo General de Población y Vivienda 2000. México: Instituto Nacional de Estadística, Geografía e Informática.

2007 "Población”, Anuario Estadístico Yucatán, <http://www.inegi.gob.mx/est/contenidos/espanol/sistemas/Aee07/info/yuc/c31_02.xls)> [Consultada el 23 de febrero del 2007.]

Lewin Fischer, Pedro

2007 "Yucatán as an emerging migrant-sending region", Mayan journeys. The new migration from Yucatán to the United States, Wayne Cornelius, David Fitz- 
gerald y Pedro Lewin Fischer (eds.). La Jolla [Estados Unidos]: University of California, San Diego, Center for Comparative Immigration Studies, $1-26$.

López, Felipe H. y David Runsten

2004 "El trabajo de los mixtecos y los zapotecos en California: experiencia rural y urbana”, Indígenas mexicanos migrantes en Estados Unidos, Jonathan Fox y Gaspar Rivera-Salgado (coords.). México: Cámara de Diputados, LIX Legislatura / University of California, Santa Cruz / Universidad Autónoma de Zacatecas / Miguel Ángel Porrúa, 277-309.

Macossay V., Mauro y Ma. Eugenia Castillo B.

1986 Telchac Pueblo: una comunidad henequenera. México: Universidad Autónoma Chapingo.

Mattiace, Shannan L.

2009 "Ethnic mobilization among the Maya of Yucatán", Latin American and Caribbean Ethnic Studies, 4 (2), July: 137-169. Londres: Routledge.

Máas Collí, Hilaria

1991 La importancia de las ceremonias y prácticas religiosas en una comunidad rural, Sotuta, Yucatán. Informe de investigación, UCS-CIR “Dr. Hideyo Noguchi”. Mérida: Universidad Autónoma de Yucatán.

Millet Cámara, Luis A. y Ella Fanny Quintal Avilés

1994 “Traje regional e identidad”, I’inaj: Semilla de Maíz. Revista de Divulgación del Patrimonio Cultural de Yucatán, 8 (agosto): 25-34. Mérida: Instituto Nacional de Antropología e Historia / Consejo Nacional para la Cultura y las Artes / Cultur.

Moctezuma Zamarrón, José Luis

2001 Entre pascolas y venados. Adaptación, cambio y persistencia de las lenguas yaqui y mayo frente al español. México: Siglo XXI / El Colegio de Sinaloa.

Okamura, Jonathan Y.

1981 "Situational ethnicity", Ethnic and Racial Studies, 4 (4): 452-465. Londres: Routledge.

O’Connor, Mary I.

1989 Descendants of Totoliguoqui. Ethnicity and economics in the Mayo Valley. Berkeley: University of California Press.

Quintal Avilés, Ella Fanny

2005 “Way yano'one': aquí estamos. La fuerza silenciosa de los mayas excluidos”, Visiones de la diversidad. Relaciones interétnicas e identidades indígenas en el México actual, vol. II, Miguel A. Bartolomé (coord.). México: Instituto Nacional de Antropología e Historia, 291-371. 
Quintal Avilés, Ella Fanny et al.

2003a "Solares, rumbos y pueblos: organización social de los mayas peninsulares", La comunidad sin límites. Estructura social y organización comunitaria en las regiones indígenas de México, vol. I, Saúl Millán y Julieta Valle (coords.). México: Instituto Nacional de Antropología e Historia, 293-382.

2003b “Ulu’umil maaya winiko’ob: la tierra de los mayas", Diálogos con el territorio. Simbolizaciones sobre el espacio en las culturas indígenas en México, vol. I, Alicia M. Barabas (coord.). México: Instituto Nacional de Antropología e Historia, 275-359.

Rampton, Ben

1995 "Language crossing and the problematisation of ethnicity and socialisation", Pragmatics, 5 (4): 485-513. Amberes: International Pragmatics Association.

Restall, Matthew

2004 "Etnogénesis maya", Estrategias identitarias. Educación y la antropología histórica en Yucatán, Juan A. Castillo Cocom y Quetzil E. Castañeda (eds.). Mérida: Universidad Pedagógica Nacional-Mérida / The Open School of Ethnography and Anthropology / Secretaría de Educación Pública, 33-60.

Scheffler, Lilian

1992 Los indígenas mexicanos. México: Panorama.

Solís Lizama, Mirian y Patricia Fortuny Loret de Mola

2010 "Otomíes hidalguenses y mayas yucatecos. Nuevas caras de la migración indígena y viejas formas de organización”, Migraciones Internacionales, 4 (5), julio-diciembre: 101-138. Tijuana: El Colegio de la Frontera Norte.

Suárez-Orozco, Carola y Marcelo M. Suárez-Orozco

2003 La infancia de la inmigración. Madrid: Morata.

Tec Chi, Santos A.

1981 Monografía de Telchac Pueblo, Yucatán. Mérida: Secretaría de Educación Pública / Dirección General de Culturas Populares, Unidad Regional Yucatán.

Villanueva Mukul, Eric (coord.)

1990a El henequén en Yucatán. Industria, mercado y campesinos. Mérida: Maldonado Editores / Instituto Nacional de Antropología e Historia / Cultur-Centro de Estudios para el Desarrollo Regional (Cedrac).

1990b La formación de las regiones en la agricultura. (El caso de Yucatán). Mérida, Yucatán: Maldonado Editores / Universidad Autónoma de Yucatán, Facultad de Contaduría y Administración / Centro de Estudios para el Desarrollo Regional (Cedrac). 